\title{
Perawatan Maloklusi Kelas III dengan Hubungan Skeletal Kelas III disertai Makroglosia Menggunakan Alat Ortodontik Cekat Teknik Begg
}

\author{
Pratiwi Setyowati* dan Wayan Ardhana** \\ * Program Studi Ortodonsia PPDGS Fakultas Kedokteran Gigi Universitas Gadjah Mada \\ ** Bagian Ortodonsia, Fakultas Kedokteran Gigi Universitas Gadjah Mada \\ *Jl Denta no 1 Sekip Utara Yogyakarta;, e-mail: pratiwisetyowati@yahoo.co.id
}

\begin{abstract}
ABSTRAK
Maloklusi merupakan penyimpangan letak gigi dari keadaan normal. Maloklusi dapat terjadi karena penyimpangan dental, skeletal atau kombinasi keduanya yang dapat mengakibatkan fungsi dan estetika wajah terganggu. Maloklusi kelas III muncul apabila gigi-gigi rahang bawah beroklusi lebih ke mesial dari relasi normalnya. Kasus kelas III dapat dikategorikan sebagai akibat dari maksila yang retrusi dari mandibula. Maloklusi kelas III skeletal dibagi menjadi dua yaitu maloklusi pseudo kelas III dengan mandibula normal namun maksila kurang berkembang dan maloklusi skeletal kelas III dengan mandibula yang besar. Perawatan ortodontik teknik Begg dapat digunakan untuk merawat semua jenis kasus maloklusi. Tujuan dari artikel ini adalah untuk menyajikan hasil perawatan ortodontik dengan teknik Begg pada kasus maloklusi Angle klas III dengan hubungan skeletal klas III disertai makroglosia. Pasien laki-laki umur 21 tahun mengeluhkan gigi depan yang tidak rapi dan renggang. Diagnosis: Maloklusi Angle Klas III, hubungan skeletal klas III; retrognatik maxilla dan protrusif mandibula; bidental protrusif; spacing anterior; edge to edge bite; cup to cup bite 15 terhadap 45; open bite; cross bite 12, 13 terhadap 42, 43; pergeseran garis tengah rahang atas ke kiri sebesar 2,2 mm; makroglosia. Pasien dirawat menggunakan alat cekat teknik Begg tanpa pencabutan. Kesimpulan dari hasil perawatan menunjukkan jarak gigit, tumpang gigit, cup to cup bite, cross bite, dan open bite terkoreksi. Maj Ked Gi; Desember 2013; 20(2): 184-191.
\end{abstract}

Kata Kunci: Maloklusi Kelas III, teknik Begg, makroglosia

\begin{abstract}
Class III Malocclusion Treatment with Class III Skeletal Relation with Macroglossia Using Begg Technique Orthodontical Tool. Malocclusion is a deviation from the normal position. Malocclusion may occur due to irregular dental position, skeletal or a combination of both that can lead to impaired function and facial aesthetics. Class III malocclusion occurs when the position of mandible teeth is more forward than normal relations. Class III cases can be categorized as a result of the maxillary retrusion than that of the mandible. Skeletal Class III malocclusion is divided into two pseudo class III malocclusion with normal mandible but underdeveloped maxillary and skeletal class III malocclusion with mandible over growth. The Begg technique can be used for all malocclusion. The aim of this article is to present the treatment of Class III malocclussion with skeletal class III relationship and macroglossia using Begg technique. A 21-year-old male patient complained about his anterior upper and lower teeth which were not neat and spacing. Diagnosis: malocclusion angle class III, class III skeletal relationship; retrognatic maxilla mandible protrusion; bidental protrusion; anterior spacing; edge to edge bite; cup to cup bite 15 to 45; open bite; cross bite 12, 13 to 42, 43; maxillary midline shift to the left by $2.2 \mathrm{~mm}$; macroglossia. Treatment: patient was treated with orthodontic appliance using Begg technique without extraction. After the treatment, it is found that that the overjet, overbite, cup to cup bite, cross bite and open bite could be corrected.
\end{abstract}

Maj Ked Gi; Desember 2013; 20(2): 184-191.

Keywords : class III Malocclusion, Begg technique, Macroglossia

\section{PENDAHULUAN}

Maloklusi merupakan penyimpangan letak gigi dari keadaan normal. Maloklusi dapat terjadi karena penyimpangan dental, skeletal atau kombinasi keduanya yang dapat mengakibatkan fungsi dan estetika wajah terganggu. ${ }^{1}$ Displasia skeletal merupakan suatu maloklusi yang disebabkan oleh hubungan maksila dan mandibula yang tidak harmonis. ${ }^{2}$ Klasifikasi skeletal menurut hubungan tulang rahang bawah terhadap rahang atas yaitu kelas 
I skeletal (ortognatik), kelas II skeletal (retrognatik), kelas III skeletal (prognatik). ${ }^{3}$ Maloklusi kelas III muncul apabila gigi-gigi rahang bawah beroklusi lebih ke mesial dari relasi normalnya. Kasus kelas III dapat dikategorikan sebagai akibat dari maksila yang retrusi dari mandibula. Maloklusi kelas III skeletal dibagi menjadi dua yaitu maloklusi pseudo kelas III dengan mandibula normal namun maksila kurang berkembang dan maloklusi skeletal kelas III dengan mandibula yang besar. ${ }^{4}$

Perawatan ortodontik bertujuan untuk mencapai hubungan oklusi dan fungsi yang baik, perbaikan terhadap keadaaan dentofasial dan estetis wajah, serta menghasilkan kedudukan gigi yang stabil setelah perawatan. ${ }^{1,5}$ Perawatan ortodontik dapat dilakukan dengan alat lepasan, cekat maupun kombinasi. Keunggulan alat cekat antara lain : 1) alat cekat mampu menggerakkan gigi dalam 3 dimensi yaitu arah bukolingual, mesiodistal dan oklusoapikal, 2) memberikan retensi dan stabilisasi yang baik, 3) dapat dipakai pada kasus-kasus yang sulit serta untuk gerakan-gerakan tipping, bodily dan torque. ${ }^{5,6}$

Perawatan ortodontik cekat dapat dilakukan dengan berbagai teknik. Beberapa teknik yang sering digunakan oleh klinisi diantaranya adalah teknik Edgewise, Straight Wire Appliance, dan Begg. ${ }^{7}$ Teknik Begg dikembangkan oleh Begg (1920). Secara umum, perawatan teknik Begg menggunakan kawat busur penampang bulat dengan slot vertikal sehingga perlekatan keduanya menghasilkan titik kontak tunggal dan gigi akan bergerak secara tipping. Kawat busur dilengkapi dengan loop, circle hook, anchorage bend serta berbagai auxiliary yang digunakan pada tahap tertentu seperti rotating spring dan uprighting spring. ${ }^{6}$ Prinsip pergerakan gigi pada teknik Begg adalah adanya gaya differensial dan gerakan gigi pada masing-masing tahap dilakukan secara simultan. Penggunaan mekanisme gaya differensial akan mempersingkat waktu dan mempermudah prosedur perawatan. ${ }^{8}$

Teknik Begg dibagi menjadi 3 tahap dengan tujuan tertentu, ketiga tahap tersebut saling terpisah dan dilanjutkan pada tahap berikutnya jika tahap sebelumnya telah selesai. Hal ini dimaksudkan untuk mencegah terjadinya kegagalan penjangkaran. Tujuan tahap pertama perawatan teknik Begg adalah (1)
Mencapai keteraturan letak gigi-gigi (unraveling), (2) Memperbaiki ketidakteraturan dalam arah vertikal (levelling), (3) Memperbaiki rotasi gigi anterior, (4) Memperbaiki overjet menjadi edge to edge, (5) Memperbaiki deep overbite dengan bite opening, (6) Memperbaiki crossbite, (7) Memperbaiki rotasi gigi molar dan premolar, (8) Memperbaiki diskrepansi midline. Tujuan tahap kedua adalah (1) Penutupan sisa ruang bekas pencabutan (space closing) dengan melanjutkan retraksi gigi anterior dan menarik gigi posterior ke depan, (2) Memperbaiki rotasi premolar, (3) Mempertahankan hasil yang telah dicapai pada tahap pertama. Tujuan tahap ketiga adalah (1) Mempertahankan hasil yang telah dicapai pada tahap pertama dan kedua, (2) pengaturan inklinasi aksial gigi-gigi Perawatan ortodontik teknik Begg paling sesuai untuk maloklusi klas II divisi 1, namun dapat juga untuk merawat maloklusi Angle klas I, dan klas III.8,9 Tujuan dari artikel ini adalah untuk menyajikan hasil perawatan ortodontik dengan teknik Begg pada kasus maloklusi Angle klas III dengan hubungan skeletal klas III disertai makroglosia.

\section{STUDI KASUS}

Pasien Laki-laki umur 21 tahun datang ke klinik Ortodonsia Rumah Sakit Gigi dan Mulut Prof. Soedomo Fakultas Kedokteran Gigi Universitas Gadjah Mada mengeluhkan gigi depan yang tidak rapi dan renggang (gambar, 1, 2, 3, 4 dan 5).

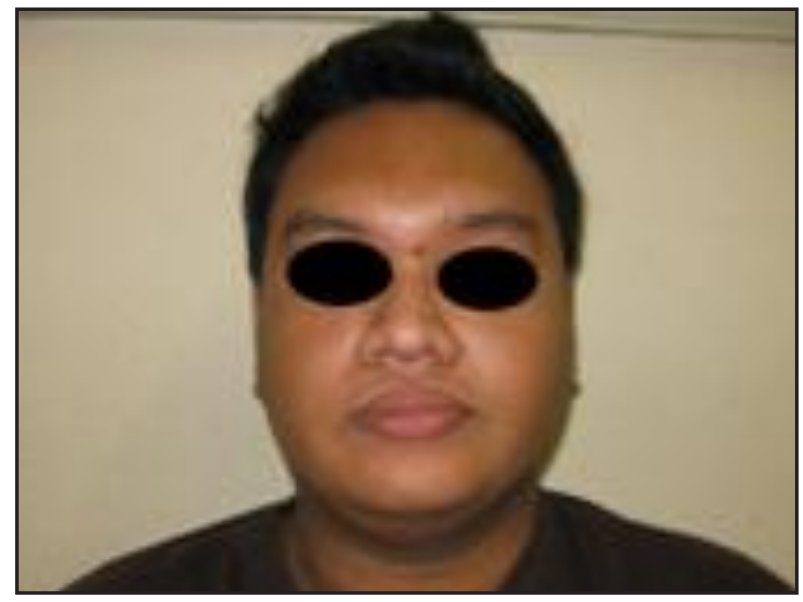

Gambar 1. Foto profil tampak depan sebelum perawatan 


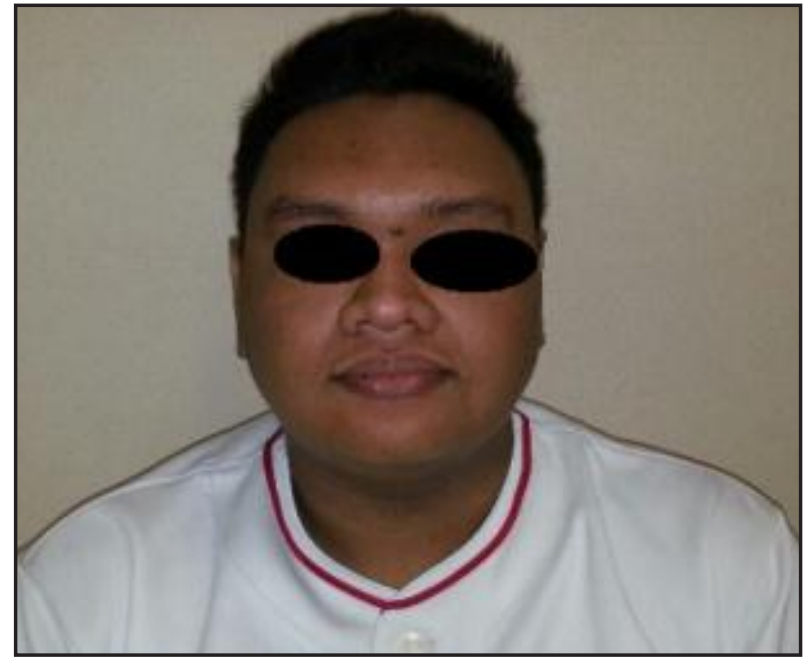

Gambar 2. Foto profil tampak depan selama perawatan

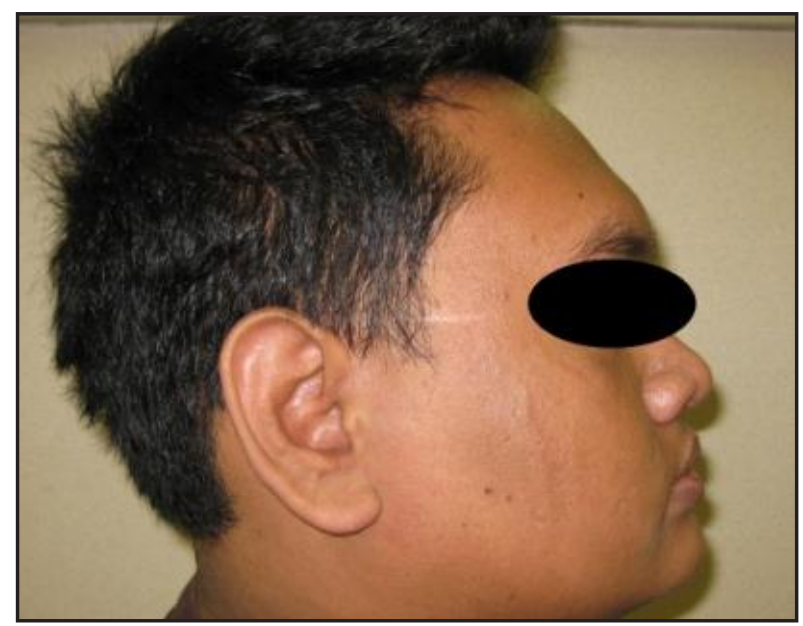

Gambar 3. Foto profil tampak samping sebelum perawatan

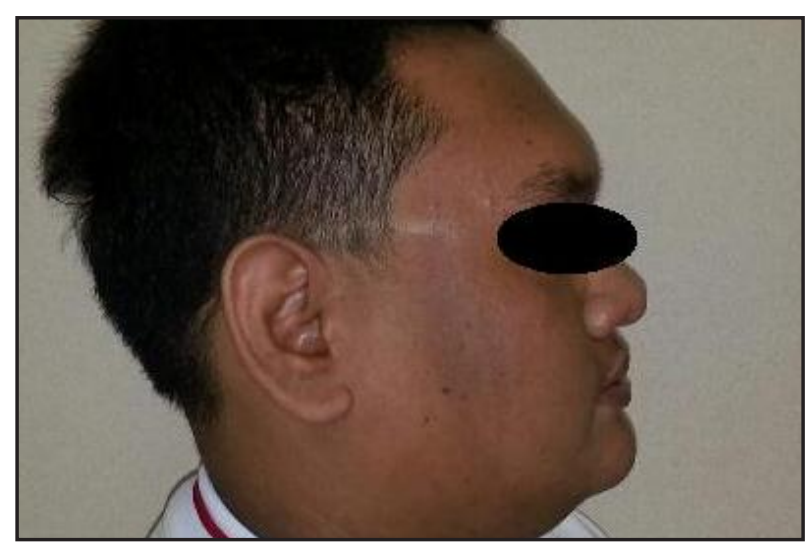

Gambar 4. Foto profil tampak samping selama perawatan

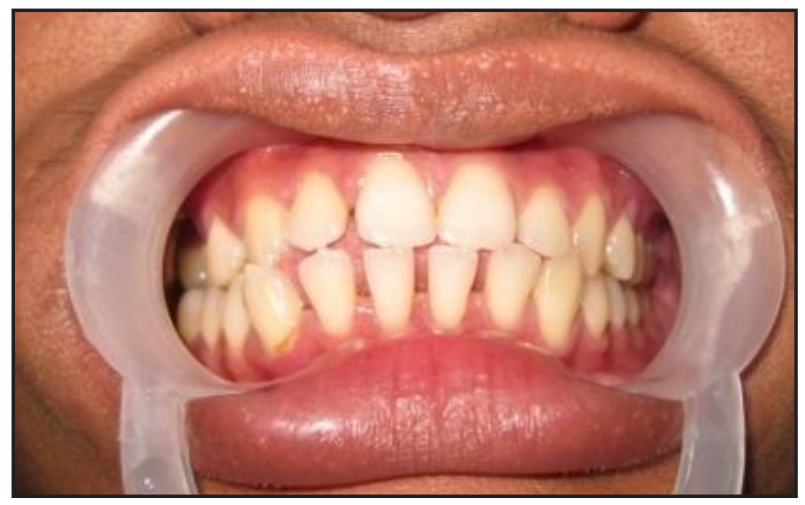

Gambar 5. Tampak depan sebelum perawatan

Pemeriksaan intra oral menunjukkan $\mathrm{OHI}$ baik, adanya crenated tongue menunjukkan ukuran lidah besar (makroglosia), pemeriksaan model studi menunjukkan palatum dari arah vertikal terlihat dalam dan lateral terlihat lebar, bentuk lengkung gigi atas dan bawah parabola asimetris. Gigi-gigi anterior atas dan bawah renggang. Hubungan gigi molar pertama sebelah kiri kelas I Angle sedangkan gigi molar pertama kanan tidak dapat ditentukan karena gigi 16 telah dicabut. Hubungan gigi kaninus kanan dan kiri kelas III Angle. Overjet $0 \mathrm{~mm}$, overbite $0 \mathrm{~mm}$, cup to cup bite 15 terhadap 45; open bite; cross bite 12, 13 terhadap 42, 43, Garis tengah rahang bawah terhadap rahang atas tidak segaris, sedangkan garis inter insisivus sentral atas terhadap garis tengah rahang bergeser ke kiri sebesar 2,2 $\mathrm{mm}$. Berdasarkan pemeriksaan riwayat keluarga, keadaan maloklusi pasien diturunkan dari ibu pasien. Berdasarkan hasil analisis sefalometri disimpulkan tipe maloklusi skeletal Kelas III dengan maksila retrusif dan mandibula protrusif serta bidental protrusif. Diagnosis kasus ini adalah maloklusi Angle klas III dengan hubungan skeletal kelas III disertai maksila retrognati dan mandibula prognati.

Perawatan yang dilakukan bertujuan memperbaiki spacing, cross bite, koreksi overjet dan overbite dengan menggunakan alat cekat teknik Begg. Berdasarkan perhitungan determinasi lengkung dan set up model Kesling, lengkung ideal pada rahang bawah disesuaikan dengan jumlah lebar mesio-distal gigi-gigi sehingga didapatkan retraksi pada rahang bawah sebesar 2,5 $\mathrm{mm}$. Rahang atas tidak dilakukan retraksi maupun protraksi agar mendapatkan overjet yang ideal hanya dilakukan pengaturan lengkung. 
Tahap perawatan disusun berdasarkan tahaptahap pada metode teknik Begg. Tujuan tahap pertama perawatan teknik Begg antara lain : mengatur letak gigi dengan koreksi buko-lingual (unravelling), memperbaiki ketidakteraturan dalam arah vertikal (levelling), koreksi hubungan insisivus dari edge to edge menjadi relasi kelas I. Perawatan dimulai dengan menggunakan busur kawat dari diameter kecil (0,014") hingga diameter besar. Gigi-gigi rahang atas dan rahang bawah dilakukan perbaikan midline. Circle hook pada rahang atas ditempatkan tepat berada pada mesial braket gigi kaninus. Circle hook pada rahang bawah berada $1 \mathrm{~mm}$ di depan braket gigi kaninus. Open coil digunakan untuk mendorong gigi-gigi anterior agar midline terkoreksi. Pertama-tama gigi 11 didorong ke distal sampai batas stopper yang telah ditentukan. Kemudian, gigi 21 didorong mendekati gigi 11 sehingga kedua insisivus sentral tepat berada pada midline wajah pasien. Setelah berada segaris dengan medianline wajah, gigi insisivus sentral dilakukan ligasi menggunakan kawat ligatur. Gigi 12 dan 22 didorong ke mesial mendekati insisivus sentral menggunakan open coil. Setelah keempat gigi insisivus rapat, dilakukan ligasi.

Pertengahan gigi insisivus rahang bawah diberi stopper agar gigi 31 dan 41 segaris dengan midline rahang atas. Rahang bawah dilakukan pergeseran midline seperti pada rahang atas. Setelah keempat insisivus rahang bawah rapat dan segaris midline kemudian diretraksi menggunakan elastik intermaksiler kelas III 5/16 2 oz agar didapatkan overjet yang positif.

Tujuan tahap kedua teknik Begg adalah penutupan sisa ruang. Sisa ruang terdapat pada rahang atas sedangkan rahang bawah tidak terdapat sisa ruang. Mesialisasi gigi-gigi posterior rahang atas menggunakan Australian wire ukuran 0,016". Satu persatu gigi-gigi posterior ditarik ke mesial. Tahap ketiga pada teknik Begg adalah memperbaiki inklinasi gigi menggunakan plainarchwire 0,020" dengan anchorage bend $15^{\circ}$ di mesial molar pertama, circle hook tepat pada mesial braket kaninus, uprighting spring untuk koreksi mesial dan distal tilting, serta rotating spring untuk koreksi rotasi gigi yang terjadi.

Setelah leveling dan unraveling gigi-gigi rahang atas dan rahang bawah tahap pertama tercapai, dilakukan pergeseran midline rahang atas dan rahang bawah. Rahang bawah diretraksi untuk mendapatkan overjet positif. Setelah dilakukan perawatan selama 2 tahun, terlihat malrelasi dan malposisi gigi individual sudah terkoreksi, overjet menjadi $2,5 \mathrm{~mm}$ dan overbite menjadi $2,6 \mathrm{~mm}$. Terdapat spacing pada regio posterior kanan rahang atas dikarenakan relaps (Gambar 6, 7, 8, 9 dan 10).

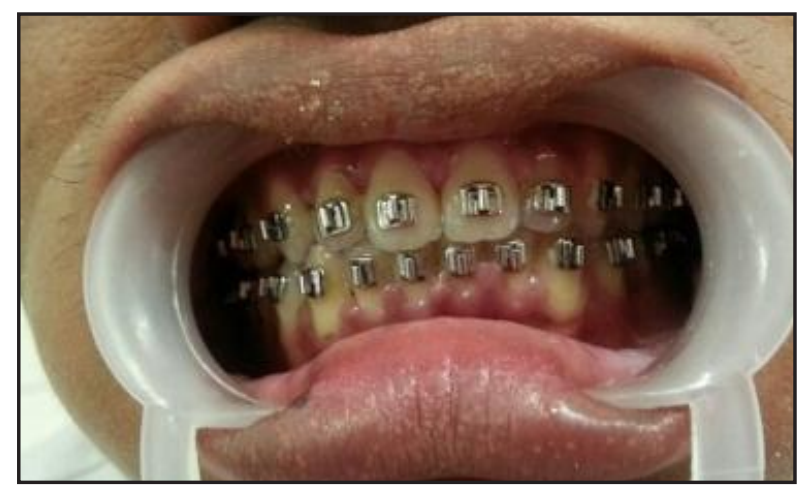

Gambar 6. Tampak depan setelah 2 tahun perawatan

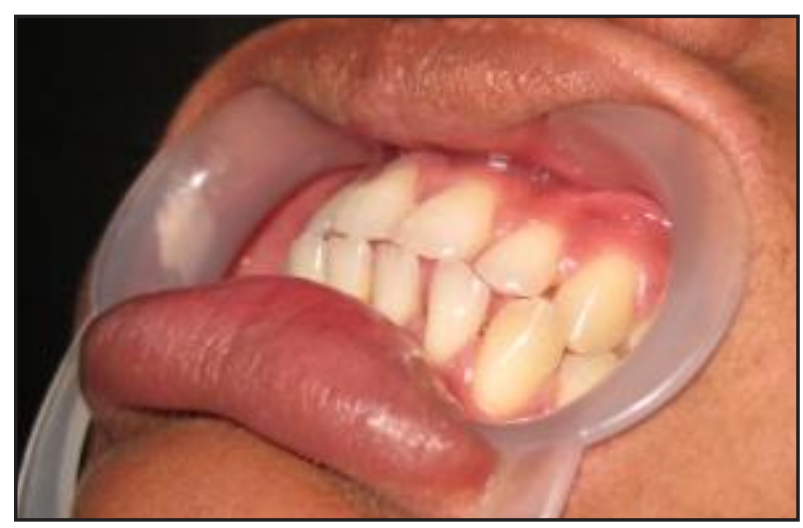

Gambar 7. Tampak samping kiri sebelum perawatan

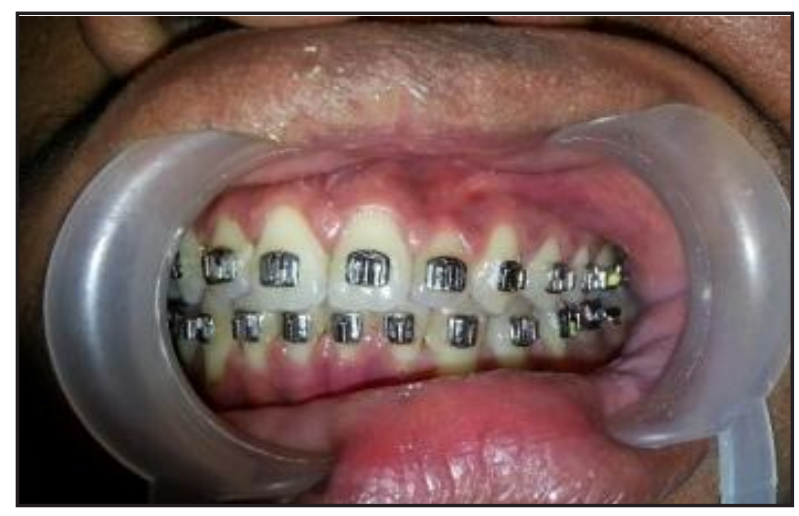

Gambar 8. Tampak samping kiri setelah 2 tahun perawatan 


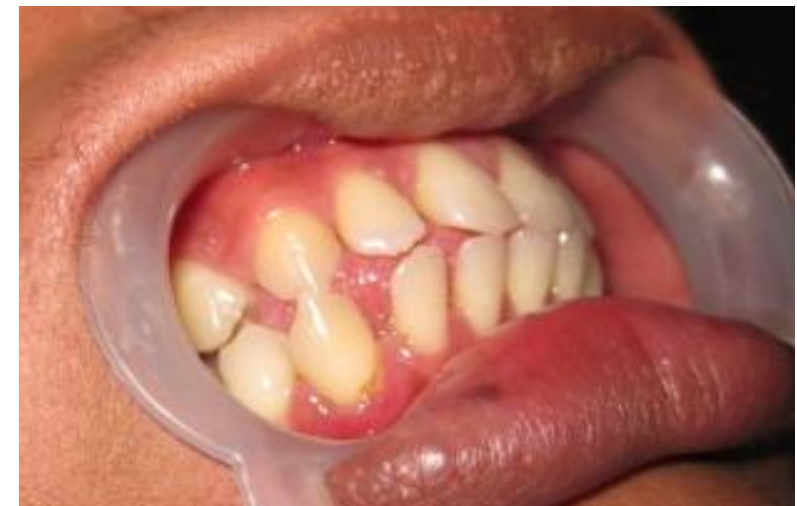

Gambar 9. Tampak samping kanan sebelum perawatan

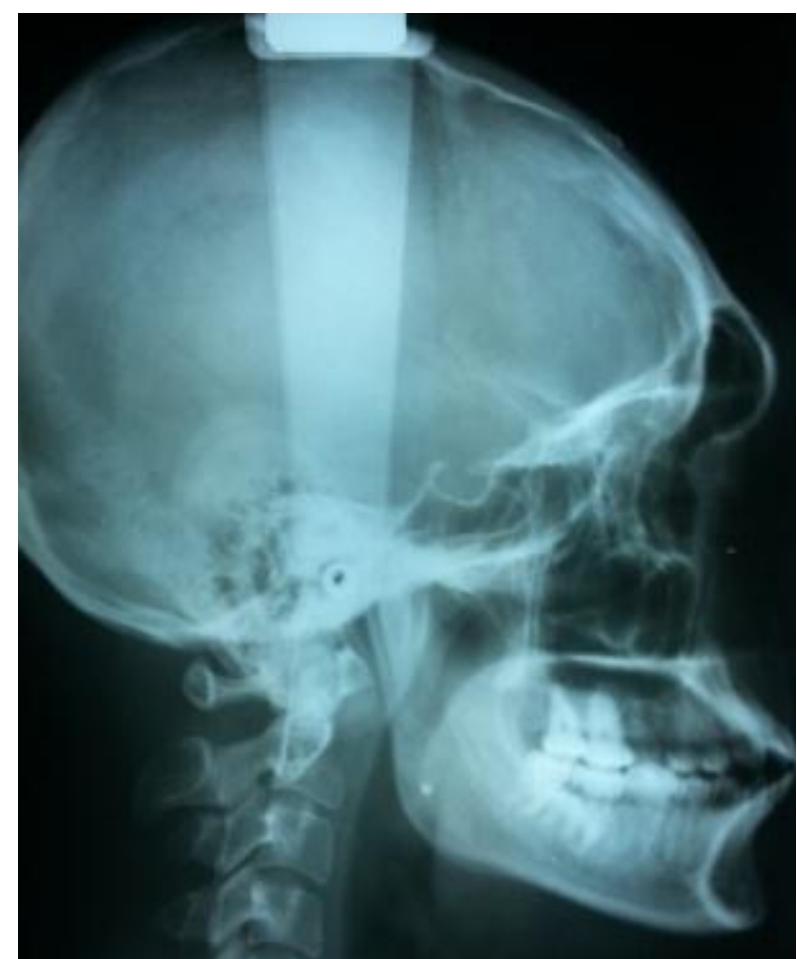

Gambar 11. Sefalometri sebelum perawatan

Pemeriksaan sefalometri sebelum pera-watan terlihat retrognati maksila dan prognati mandibula serta gigitan gigi anterior edge to edge bite.

Perawatan selama 2 tahun terlihat bahwa hubungan skeletalnya tidak berubah namun gigitan anterior telah terkoreksi. Radiografi sebelum perawatan terlihat gigi anterior atas dan bawah renggang-renggang dan sisa bekas pencabutan gigi

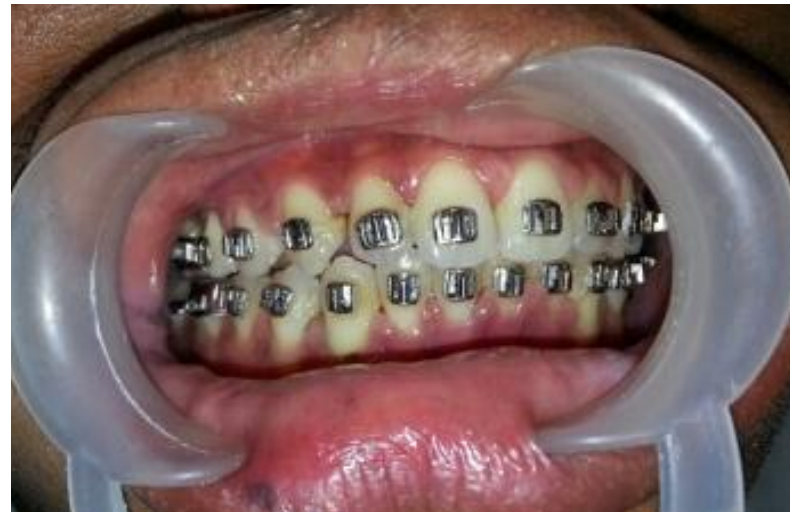

Gambar 10. Tampak samping kanan setelah 2 tahun perawatan

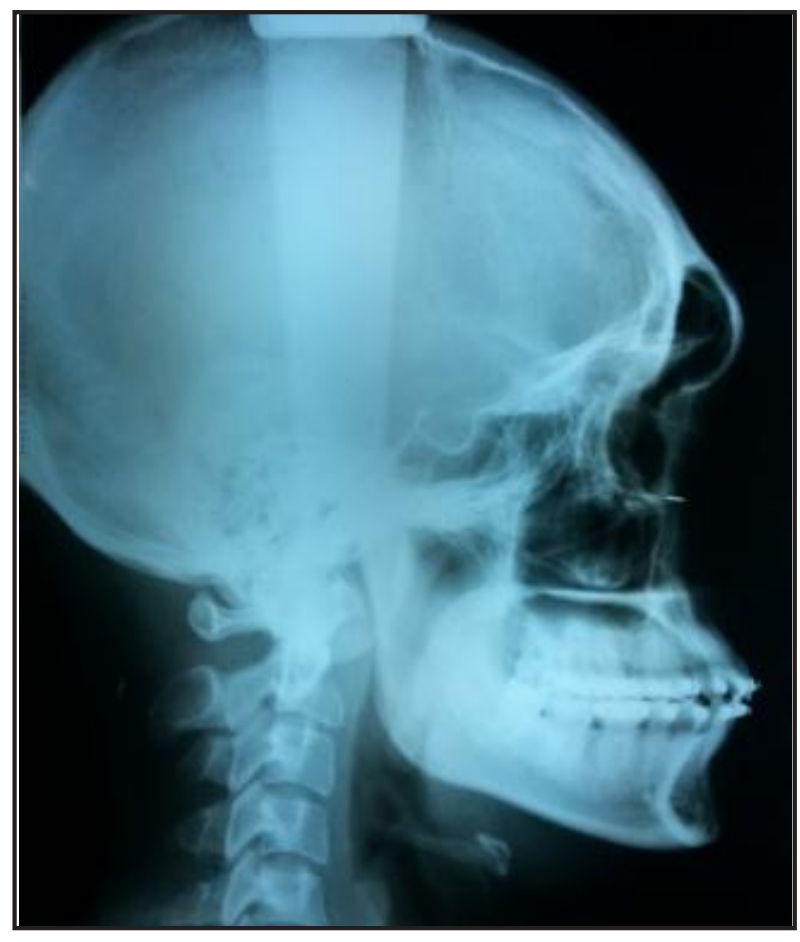

Gambar 12. Sefalometri sesudah perawatan

molar pertama rahang atas sebelah kanan. Radiografi selama perawatan 2 tahun terlihat ruang sisa bekas pencabutan dan renggang pada gigi-gigi anterior telah menutup. Hubungan molar menunjukkan kelas I (Gambar 11, 12, 13 dan14).

Tampak malposisi gigi anterior terkoreksi, namun tidak ada perubahan hubungan skeletalnya 


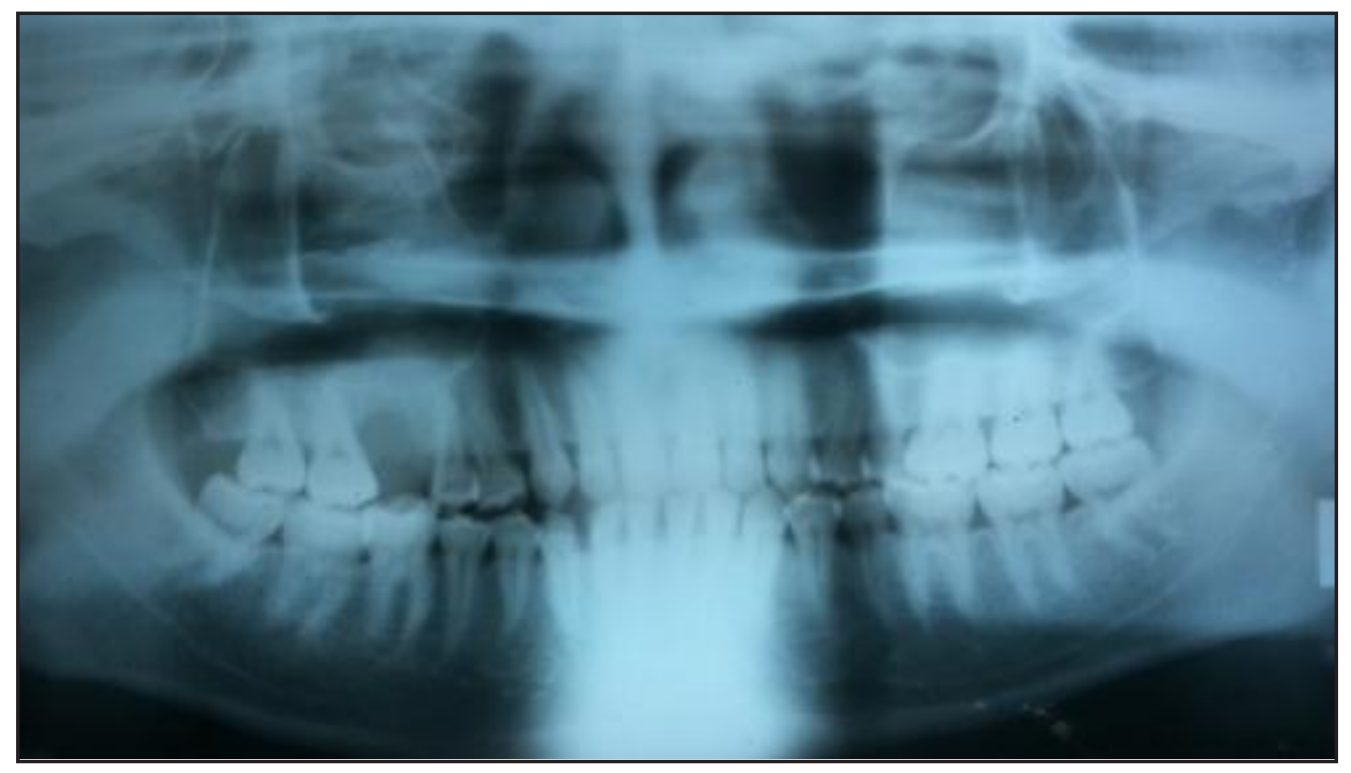

Gambar 13. OPG sebelum perawatan

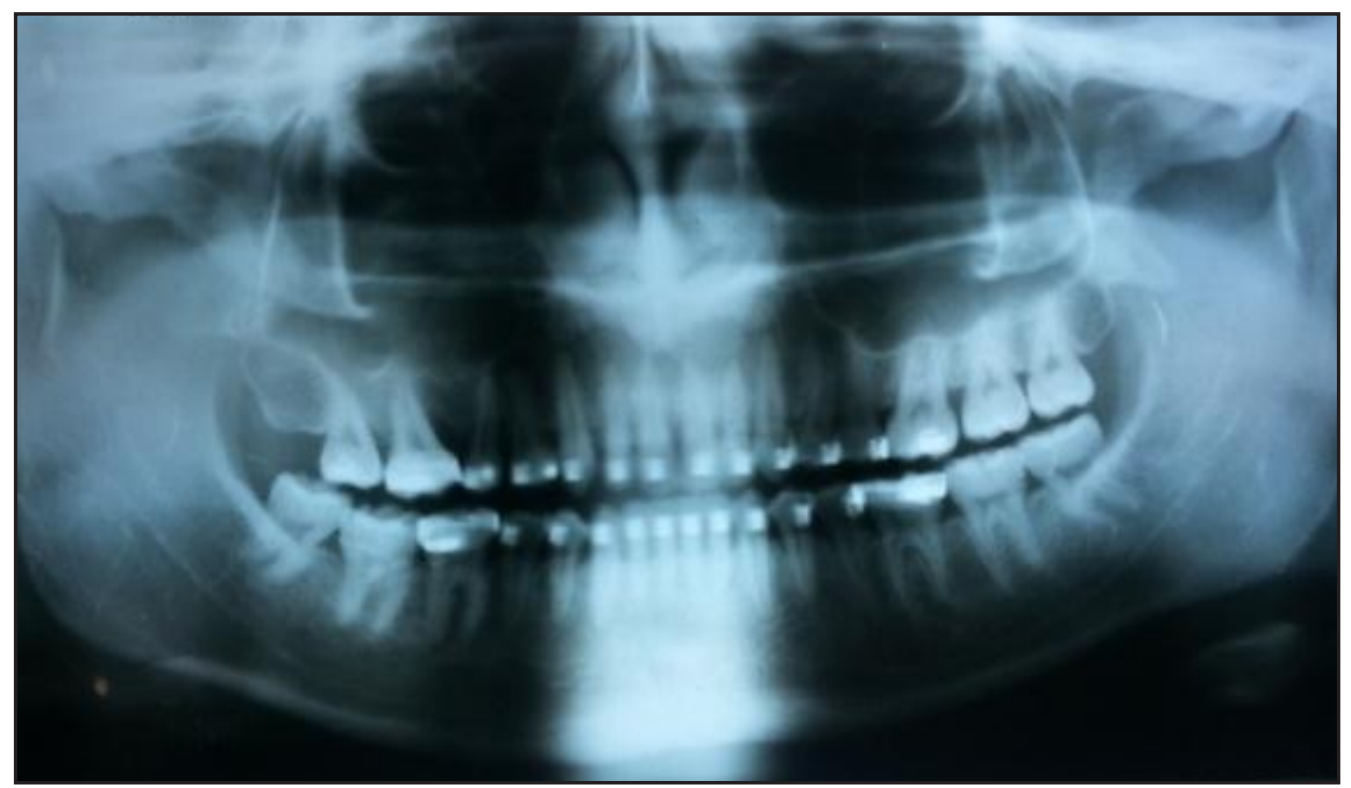

Gambar 14. OPG sesudah perawatan

\section{PEMBAHASAN}

Maloklusi adalah penyimpangan letak gigi dan atau malrelasi lengkung geligi (rahang) di luar rentang kewajaran yang dapat diterima. " Keadaan gigi yang tidak harmonis mempengaruhi estetika dan penampilan seseorang serta mengganggu fungsi pengunyahan, penelanan, maupun bicara. ${ }^{12}$ Maloklusi dapat disebabkan karena tidak adanya keseimbangan dentofasial. Secara garis besar etiologi atau penyebab suatu maloklusi dapat digolongkan dalam faktor herediter (genetik) dan faktor lokal."

Faktor herediter dapat mempengaruhi disproporsi ukuran gigi dan ukuran rahang yang menghasilkan maloklusi berupa gigi berdesakan atau maloklusi berupa diastema yang menyeluruh (multipel diastema, serta disproporsi ukuran, posisi dan bentuk rahang atas dan rahang bawah yang menghasilkan relasi rahang yang tidak harmonis. 
Faktor lokal dapat menyebabkan berbagai maloklusi tergantung penyebabnya. Suatu maloklusi sukar ditentukan secara tepat etiologinya karena adanya berbagai faktor (multifaktor) yang mempengaruhi pertumbuhan dan perkembangan. ${ }^{11}$

Makroglosia merupakan suatu keadaan lidah yang mempunyai ukuran lebih besar dari normal. ${ }^{13}$ Makroglosia dapat disebabkan oleh karena hipertrofi otot lidah namun juga dapat merupakan kelainan yang didapat, selain karena faktor perkembangan. ${ }^{14}$ Tekanan otot lidah merupakan faktor penting dalam perkembangan rahang bawah. Makroglosia menimbulkan pengaruh yang besar bagi perkembangan rahang selain itu makroglosia juga dapat menyebabkan prognatisme mandibula yaitu tulang mandibula yang maju, sehingga terjadi maloklusi pseudo klas III. ${ }^{15,16}$ Lidah yang membesar dan keluar dari rongga mulut yang menyebabkan penderita berusaha menutup mulutnya sehingga lama-kelamaan mandibula terlihat seperti protrusi. Hal inilah yang menyebabkan maloklusi pseudo klas III. ${ }^{17}$ Makroglosia dapat menyebabkan maloklusi pada gigi. Makroglosia juga dapat menimbulkan maloklusi pada gigi dan rahang seperti crossbite, openbite dan prognatisme mandibula. Kasus yang paling sering pada penderita makroglosia adalah crossbite dan openbite. ${ }^{13}$

Gigitan terbuka/open bite adalah keadaan adanya ruang oklusal atau insisal dari gigi saat rahang atas dan rahang bawah dalam keadaan oklusi sentrik. ${ }^{18}$ Gigitan terbuka dapat diklasifikasi sebagai open bite skeletal atau open bite dental. Gigitan terbuka dental mempunyai prognosis yang lebih baik dibandingkan gigitan terbuka skeletal. ${ }^{19}$

Pemeriksaan klinis pada pasien ditemukan adanya crenated tongue sehingga didiagnosa sebagai makroglosia. Pada kasus ini maloklusi juga disebabkan karena faktor keturunan, diketahui dari hasil anamnesa, dimana ibu memiliki keadaan gigi yang mirip dengan pasien. Diastema multipelgigigigi anterior pasien disebabkan karena ukuran lidah yang besar/makroglosia. Penutupan space dilakukan setelah dilakukan pergeseran midline terlebih dahulu memakai open coil. Malrelasi yang ditemukan pada saat pemeriksaan klinis adalah open bite. Open bite pada pasien adalah tipe dental sehingga dapat terkoreksi dengan pemakaian alat ortodontik cekat teknik Begg.

Kesulitan perawatan pada kasus ini adalah kestabilan dari hasil perawatan. Etiologi dari kasus ini adalah adanya makroglosia.Setelah gigi-gigi anterior rapat harus dilakukan ligasi agar dapat menahan agar hasil perawatan menjadi stabil/tidak relaps. Perawatan untuk setiap kasus makroglosia harus dievaluasi dengan hati-hati. Perawatan makroglosia dapat dilakukan dengan tindakan bedah dan maloklusi gigi yang ditimbulkan makroglosia dapat dikoreksi dengan perawatan ortodonti. Perawatan bedah dilakukan hanya saat perawatan ortodontik tidak berhasil. ${ }^{10}$

Pada kasus ini, untuk mengatasi relaps gigi-gigi yang telah terkoreksi dengan menggunakan plain archwire dengan circle hook tepat berada ada mesial braket gigi kaninus kemudian diligasi antara braket dengan circle hook. Berdasarkan cetakan studi model dan foto intra oral telah terjadi koreksi edge to edge bite, spacing, crossbite, openbite pada gigi-gigi rahang atas dan rahang bawah.pasien diinstruksikan untuk memakai retainer selama seumur hidup agar perawatan ortodontik berhasil dengan baik.

\section{KESIMPULAN}

Perawatan ortodontik maloklusi kelas III menggunakan alat ortodontik cekat teknik Begg menunjukkan hasil yang cukup baik. Overjet, overbite, malposisi gigi-gigi individual dan malrelasi dapat terkoreksi. Stabilitas hasil perawatan kurang stabil dikarenakan ukuran lidah dari pasien yang besar / makroglosia. Oleh karena itu, pasien diinstruksikan untuk memakai retainer seumur hidup agar hasil perawatan stabil.

\section{DAFTAR PUSTAKA}

1. Graber TM, Swain BF. Orthodontic current principles and technique. Ed 3. Philadelphia: WB Saunders Company; 1985.

2. Moyers RE. Handbook of orthodontics. Ed 3. Chicago: Year-Book Medical; 1997. H. 183-95.

3. Darendeliler A, Kharbanda O. Occlusion and clinical practise an evidence based approach. Ed 1. Edinburgh: Elsevier limited; 2004. H. 91-5. 
4. Tweed $\mathrm{CH}$. Clinical orthodontics. Vol 2. Mosby: St Louise; 1966.

5. Proffit WR. Contemporary orthodontics. Ed 3. St.Louish: The CV Mosby Co; 2000. H. 385-8.

6. Begg PR, Kesling PC. Begg orthodontic theory and technique. Ed 3. Philadelphia: WB Saunder Co; 1977. H. 87-89.

7. Bhalajhi SI. Orthodontics the art and scienc e.Ed 3. New Delhi : Arya (MEDI) Publishing House; 2004.

8. Cadman CAR. A Vademecum for the begg technique: Technical Pricipal. Am. J. Orthod. 67(5): 439-512.

9. Fletcher GCT. The begg appliance and technique, Biston: John Wright \& Sons (print) Ltd; 1981. H. 273-8.

10. Gasparini G, Saltarel A, Carboni A, Maggiulli F, Becelli R. Surgical management of macroglossia. Oral Surg Oral Med Oral Pathol Oral Radiol Endod. 2002; 94: 566-71.

11. Rahardjo P. Ortodonti dasar. Surabaya: Airlangga University Press; 2009. H. 26

12. Lee W, Wong RW. Non-surgical orthodontic treatment of anterior open bite. Hong Kong Dent J. 2009; 6: 103-7.
13. Dewi O. Analisis hubungan maloklusi dengan kualitas hidup pada remaja SMU Kota Medan tahun 2007 [PhD thesis]. USU e-Repository: 2008.

14. Langlais RP, Miller CS. Atlas berwarna kelainan rongga mulut yang lazim. Alih bahasa: Budi Susetyo. Jakarta : Hipokrates; 1994. H. 24, 42-45, 58, 82

15. Sudiono J. Gangguan tumbuh kembang dentokraniofasial, Jakarta: ECG; 2009. H.13, 72.

16. Lynch MA, Brightman VJ, Greeberg MS. Burket ilmu penyakit mulut, diagnosis dan terapi. Alih bahasa: Sianita Kurniawan. Jakarta: Binarupa Aksara; 1994. H. 523-35

17. Graber TM, Neuman B. Removable orthodontic appliance. Ed 2. Philadephia: W.B Saunder Company; 1984. H.153-8.

18. Asnindar. Makroglosia : Pengaruhnya pada pertumbuhan dan perkembangan anak. [Skripsi]. Sumatera Utara: Fakultas Kedokteran Gigi Universitas Sumatera Utara; 2005. p.13

19. Burford D, Noar JH. The cause, diagnosis and treatment of anterior open bite. Dent Update. 2003; 85: 28-36.

20. Lee W, Wong RW. Non-surgical orthodontic treatment of anterior open bite. Hong Kong Dent J. 2009; 6: 103-7. 